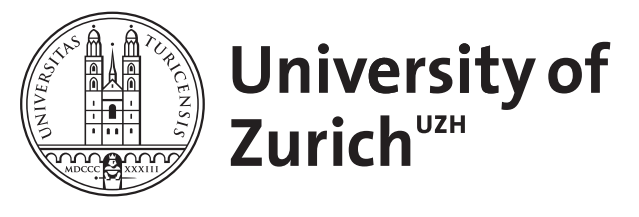

\title{
The concept of a living tradition
}

Beckstein, Martin

\begin{abstract}
Starting with Popper, social theorists across the board have acknowledged that traditions serve socially valuable functions. However, while traditions are usually understood as 'living' entities that come in overlapping varieties and evolve over time, the socially valuable functions attributed to tradition tend to presuppose invariability in ways of thinking and acting. Addressing this tension, this article provides a detailed analysis of the concept of tradition, and directs special attention to conceivable criteria for the authentic continuation of a tradition. It is argued that the ways of thinking and acting that constitute the material of a tradition must - among faithful members of that tradition - stand in a relation of equivalence - not identity or similarity. The implications of this account concern our ability to decide (normatively) conflicts over authenticity among rival tradition branches as well as the role that traditions play in policy-making
\end{abstract}

DOI: https://doi.org/10.1177/1368431016668185

Posted at the Zurich Open Repository and Archive, University of Zurich

ZORA URL: https://doi.org/10.5167/uzh-140570

Journal Article

Originally published at:

Beckstein, Martin (2017). The concept of a living tradition. European Journal of Social Theory, 20(4):491-510.

DOI: https://doi.org/10.1177/1368431016668185 
European Journal of Social Theory 2017, Vol. 20(4) 491-510 (c) The Author(s) 2016 Reprints and permission: sagepub.co.uk/journalsPermissions.nav DOI: $10.1177 / 1368431016668185$ journals.sagepub.com/home/est

(SAGE

\author{
Martin Beckstein \\ University Center for Human Values, Princeton University, USA
}

\begin{abstract}
Starting with Popper, social theorists across the board have acknowledged that traditions serve socially valuable functions. However, while traditions are usually understood as 'living' entities that come in overlapping varieties and evolve over time, the socially valuable functions attributed to tradition tend to presuppose invariability in ways of thinking and acting. Addressing this tension, this article provides a detailed analysis of the concept of tradition, and directs special attention to conceivable criteria for the authentic continuation of a tradition. It is argued that the ways of thinking and acting that constitute the material of a tradition must - among faithful members of that tradition stand in a relation of equivalence - not identity or similarity. The implications of this account concern our ability to decide (normatively) conflicts over authenticity among rival tradition branches as well as the role that traditions play in policy-making.
\end{abstract}

\title{
Keywords
}

authenticity, change, institutions, Popper, tradition

Enlightenment rationalists considered traditions to be obstacles to the development of true knowledge and good social order. Traditions, they suggested, are shackles of the past that prevent people from moving on and realizing justice. Policy-making should bow to the authority of reason, not the force of habit. According to Popper, rationalists had taken too easy a way out. While traditions cannot replace normative reasoning in policy-making, he argued (Popper, 1972), it would be reckless to discard them out of hand as the irrational remnants of primitive societies. What we need, Popper claimed, is a

\section{Corresponding author:}

Martin Beckstein, University Center for Human Values, Princeton University, 306 Marx Hall, Princeton, NJ 08544, USA.

Email: mjbeckstein@gmail.com 
rational theory of tradition; a theory that manages to rescue traditions from the traditionalists and, to some extent, rationality from the rationalists.

Popper's article, 'Towards a rational theory of tradition' marks a watershed in scholarly debate about tradition because ever since, or so it seems, the task is generally understood as one of overcoming the dichotomy of traditionality and rationality, of formed ways of thinking and acting, on the one hand, and abstract normative reasoning, on the other. More specifically, Popper and later scholars following this path have argued that traditions may serve valuable functions for private and public life by, for instance:

providing guidance concerning the timing and manner of complying with imperfect duties articulated by philosophical principles;

creating a 'home' in time and enacting (as well as assuring oneself of) one's individual or collective self-persistence;

embodying and entrenching habits as well as social conventions;

serving as containers for practical knowledge and accumulated historical experience

('wisdom'); or

guiding laws, as long as the legal regime conforms to traditions people will accept them as a form of legitimate authority. ${ }^{1}$

Following Scheffler, I conceive of traditions as sets of beliefs, customs, teachings, values, practices, or procedures that are transmitted from generation to generation (cf. Scheffler, 2010: 290). This understanding is broad enough to capture macro-cultural phenomena that contributions akin to communitarianism consider paradigmatic such as national traditions (e.g. Wall, 2015), even though perhaps not quite rationalities (e.g. MacIntyre, 1997). However, to reduce complexity, this article illustrates its argument mostly by reference to micro-cultural phenomena that partially rather than holistically regulate private and public life, such as the bequest of dress watches by heads of families to their descendants, marriage, Christian caritas, and Hegelianism. As far as I can see, this methodological decision greatly facilitates comprehension without simplifying matters in a meaningful way.

The aim of this article is to develop an informative understanding of the authentic continuation of tradition. ${ }^{2}$ The article therefore deals with the flipside of the already ample scholarship on factitious continuity claims, i.e. the 'invention of tradition' (Hobsbawm, 1983), and indirectly comments on it. This choice of focus is motivated by the fact that the two models for the authentic continuation of a tradition that can be found in the literature are both wanting. The first model suggests that members of a later generation must have the same set of beliefs (or customs, etc.) as the members of the previous generation to be faithful inheritors of their tradition (Hobsbawm, 1983: 2; Pieper, 2010). This understanding appears to be under-inclusive because the underlying causal-identity criterion allows for neither intra- nor inter-generational variance in the relevant set of beliefs (or customs, etc.). The second model suggests that traditions are capable of accommodating changes in their meaning over time as well as withstanding disagreement over their meaning among simultaneously existing adherents (e.g. MacIntyre, 1992: 222; Oakeshott, 1965, 1991; Wall, 2015: 4). Usually, very little is said about why, how, how much, and in regard to what such inter- and intra-generational heterogeneity is 
permissible. If a criterion is explicitly given, then it is causal similarity. ${ }^{3}$ This criterion, however, appears to be over-inclusive and arbitrary as it permits any modification in a given set of beliefs (or customs, etc.) as long as this set develops slowly over time. Hence, there is a need for a more informative formal understanding of the act of authentically continuing a tradition and the act of breaking with it. The lack of conceptual clarity also inhibits our understanding of the normativity of tradition, which constitutes a second shortcoming of the existing literature: while most theorists favour the second model that considers traditions to be 'living' entities, they assign roles to traditions (see the above list) that tend to require stasis and concurrence in ways of thinking and acting. Intra- and inter-generational variation in the meaning of traditions quite obviously seems to be negatively correlated with the socially valuable functions that traditions are supposed to serve. This tension has not been sufficiently discussed so far, and neither has it been considered whether any positive effects result from the 'living' nature of traditions.

To address these desiderata, the first section takes Popper's 'Towards a rational theory of tradition' as a starting point. The two shortcomings of the existing literature are reflected in, if not inspired by, Popper's ambiguous characterization of traditions as both uniform and heterogeneous. I then distinguish the two existing models of traditions and show why they are wanting. The third section develops an alternative model of tradition that requires causal equivalence of the overall point or purpose of the set(s) of beliefs (or customs, etc.) among faithful members of a tradition. It suggests that traditions not only may but in fact must change as time goes by, namely, in such a way as to counterbalance relevant changes in the individuals' respective contexts of living. The fourth section examines how this alternative understanding shapes our understanding of the functions of traditions, focusing in particular on their role in policy-making. Given that traditions divide their adherents as much as they attune their ways of thinking and acting, I conclude that some socially valuable functions that frequently are attributed to traditions must be relativized. However, the proposed conception suggests positively, and somehow unexpectedly, that traditions can serve as catalysts for institutional reform.

\section{Popper's reappraisal of traditions}

In 1948, Popper (1972: 120-1) expressed the concern that rationalists since the Enlightenment had kept a self-refuting 'traditional attitud[e] towards the problem of tradition'. They simply assumed, without actually scrutinizing this assumption, that traditions were detrimental to attempts to develop a good social order. To overcome this self-refuting attitude and ward off the challenge posed by (neo-)traditionalists such as Burke, Hayek, and Oakeshott, Popper reflected on the cornerstones of a rational theory of tradition. ${ }^{4}$ This section recalls his reflections, showing how Popper attempts to reconcile formed ways of thinking and acting with abstract reasoning, but still leaves important questions concerning traditions unanswered.

A basic outlook that Popper shares with (neo-)traditionalists is the view that social order consists in an immensely intricate web of functionally interdependent regulations and arrangements. Traditions are a major and indispensable part of this intricate web. They almost always come into being as unintended by-products of action, with Popper noting that many of them will be imperfect. They may include inappropriate beliefs 
about the world and call for the performance of unjust acts. Yet regardless of whether they are particularly appropriate and just, traditions as such bring order and continuity to an otherwise chaotic world, as well as predictability, and thus facilitate individual and collective rational action:

We should be anxious, terrified, and frustrated, and we could not live in the social world, did it not contain a considerable amount of order, a great number of regularities to which we can adjust ourselves. The mere existence of these regularities is perhaps more important than their peculiar merits or demerits. They are needed as regularities, and therefore handed on as traditions. (Popper, 1972: 130)

Two functions of traditions emerge from Popper's characterization at this point. Using Scheffler's (2010: 291) distinction, we can say that traditions, for Popper, embody and entrench social conventions as well as collective habits. Whereas social conventions (e.g. red traffic lights used as stop signs) foster the coordination of behaviour, collective habits allow people to gain 'deliberative efficiency' in that they equip the members of a new generation with tacit knowledge and habitual practices without their having to become active and waste scarce resources reflecting on every course of action in which they must engage daily.

Since particular traditions may be unjust or inadequate, Popper affirms, it is necessary to question them by employing the independent criterion of normative principles. If a tradition is found to be wanting, one might consider replacing it with another transplanted from somewhere else. Substituting it with a newly invented construct is not a viable option in Popper's view. ${ }^{5}$ As a result, rationality is neither the enemy of nor a substitute for traditions; it is primarily a tool for making good selections from the various particular traditions that have brought order to social life at different times and in different places (Popper, 1972: 122, 132).

Besides showing that traditions enhance ordered social life and proposing a view that reconciles traditions and rationality, Popper tried to specify the relationship between traditions and institutions. Whereas traditions 'describe a uniformity of people's attitudes, or ways of behaviour, or aims or values, or tastes' (p. 133), Popper proposes that we understand institutions as

(changing) bod[ies] of people [that] observe a certain set of norms or fulfil certain prima facie social functions (such as teaching, policing ... ) which serve certain prima facie social purposes (such as the propagation of knowledge, or protection from violence). (p. 133)

A permanent danger for institutions, Popper suggests, is that persons run them in such a way as to serve their own purposes. Officers may accept bribes and thus participate in crime rather than preventing and prosecuting them, while teachers may propagate personal opinions instead of knowledge. Traditions are intermediaries, Popper suggests, that push personnel towards running institutions properly: "[T]he long-term "proper" functioning of institutions depends mainly upon ... traditions. It is tradition which gives the persons (who come and go) that background and that certainty of purpose which resist corruption' (p. 134). The logic of Popper's argument here parallels a point made in legal 
philosophy concerning customary law and the benefits of a tradition-oriented approach in legislation. Laws that are disconnected from traditions possess little authority. They may command obedience, but "will lack what Hart calls the "internal aspect" of rules: such laws will just not serve as standards by which members of the community judge behaviour in terms of right or wrong' (Nyíri, 1995: 24).

With this, Popper had made a considerable step towards a rational theory of tradition. Yet it is worthwhile pointing out a tension in his implicit and explicit depictions of the characteristics of traditions because it is reflected in much of the existing literature on the subject. On the one hand, Popper frequently suggests that traditions are uniform and static entities. He understands that adherents to a tradition share those ways of thinking and acting that are called for by that tradition. Because traditions attune the behaviour of individuals within and across generations they can serve the function of embodying and entrenching social conventions and collective habits. He also says that the critical assessment of a tradition may lead to its acceptance or rejection, but not to its modification. That a tradition is altered 'happens only very rarely' (Popper, 1972: 125), but if it happens, he says, we experience the creation of a new tradition rather than the continuation of an existing one. Thus, traditions are depicted as non-changing entities.

On the other hand, however, there is some reason to believe that Popper, if pressed, would not insist on this portrayal. His analogies to scientific theories suggest that traditions actually come in many, slightly diverging, versions and are occasionally developed further. He also remarks at one point that something (hence, not everything) of a tradition founder's attitude is preserved in later generations' ways of thinking and acting, from which one might take that the sets of beliefs, customs, teachings, values, practices, or procedures acquired by adherents to a tradition merely overlap, rather than coincide. Not least, Popper notes in passing that 'we naturally speak of living traditions' (1972: 127, 133).

Perhaps Popper means that traditions inform contemporaries more or less identically even though they evolve over time. But this would still raise a few questions: how much may a tradition be modified by a later generation before it has effectively been abandoned? What criterion allows us to distinguish between permissible and impermissible modifications? How much of the founder's attitude must persist in later generations' ways of thinking and acting to qualify as an authentic continuation of a tradition. Will traditions, if their meaning changes over time, still warrant the longterm proper functioning of institutions? And if not, might they be of relevance for institutions in other ways?

Such questions are neither sufficiently answered in 'Towards a rational theory of tradition', nor, as far as I can see, by later contributions to the debate. To provide the ground for answering them and taking Popper's project one step further, we need to analyse and distinguish different models of tradition in detail.

\section{Models of traditions}

Tradition, as a descriptive category, is often used to signify a set of beliefs, customs, teachings, values, practices, or procedures (or any combination of these) that is transmitted from generation to generation. The term, however, is frequently employed with 
differing meanings in the literature. For instance, 'tradition' is also used to characterize a set of beliefs (or customs, etc.) that people once held, the act of transmitting such a set or the overall process of handing it down, the process by which we have acquired certain beliefs (or customs, etc.), or the result of having internalized these. These meanings ought to be disambiguated. To do this, it is helpful to consider the threefold valence of the verb 'to hand down' (or 'to pass on'): somebody hands something down to someone else. Put more technically, a tradent (T) passes on some tradition material (M) to a recipient (R). Following Dittmann (2004: 326), I will call a single act of such transmission a tradition act. A tradition, I suggest, requires at least one successful tradition act. By analysing the three elements that constitute a tradition act, we shall see what exactly this implies.

A tradition material can, in principle, be anything: a belief, custom, teaching, practice, or procedure, but seemingly also a material object such as a dress watch that is passed on from parents to descendants. (An advertisement for a Swiss watch manufacturer reads accordingly 'Begin your own tradition: You never actually own a Patek Philippe, you merely look after it for the next generation'). Yet, as Shils has convincingly argued, even in the case of a material object, the decisive point is that a tradition material presents or implies 'patterns or images of actions ... and the beliefs requiring, recommending, regulating, permitting, or prohibiting the re-enactment of those patterns' (1981: 12). It is not the dress watch itself that is the tradition material but rather the practice of making, the ceremony accompanying, and the considerations motivating such a transfer, for instance, the symbolic preparation of children for adult roles. ${ }^{6}$

A recipient is an agent who receives a tradition material. He or she may hand it down in turn, yet may also fail or refuse to do so; and if an entire generation of recipients of a tradition material happens to fail or refuse to hand it down, the tradition comes to an end. While the recipient of a tradition can become a tradent or not, any tradent of a tradition material must necessarily have been a recipient before. Were this not the case, he or she would not hand the tradition material down, but rather over. Somewhat special is the category of the originator $(\mathrm{O})$ of a tradition. The originator is a person, group, or actant who voluntarily or involuntarily transmits some of his/her/its peculiar ways of thinking or acting to somebody. The originator of a tradition precedes the first tradition act by really handing over, rather than down, the tradition material. But this means that he/she/it will be an originator of a tradition only if the first recipient passes it on (otherwise, nothing has been handed down by somebody to somebody else). Thus, the originator of a tradition is an ex post facto category. A father may try to start a tradition when giving a luxury dress watch to his child and be retrospectively glorified as the 'founder' of the tradition. But this father has no control over whether his child passes on the dress watch to his or her descendant. Traditions do not come into being by invention; they require one successful tradition act. $^{7}$

\section{The static model of a tradition}

The basic model of a tradition takes the form of a one-one chain of transmission in that the different generations of recipients and tradents each comprise a single agent (Figure 1). 




Figure I. Basic model of a tradition.

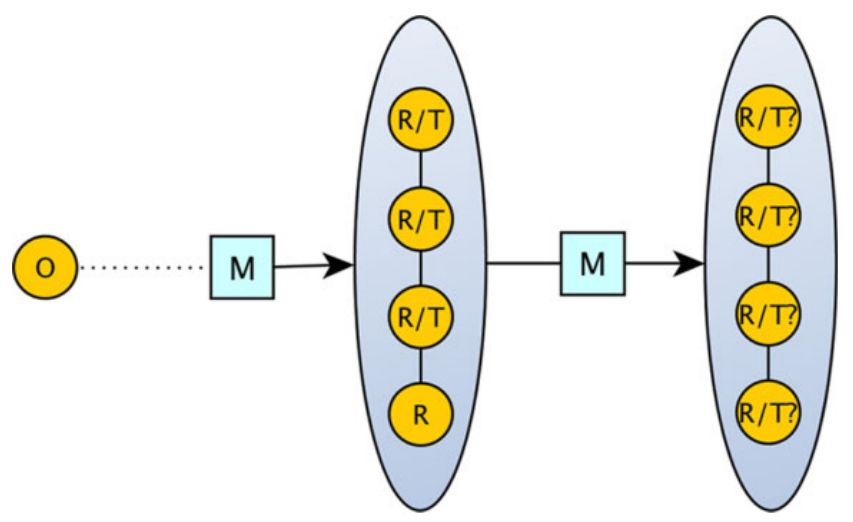

Figure 2. The static model of a tradition.

But traditions are social phenomena that include vast numbers of recipients and tradents within each generation. Accordingly, it could be understood as taking the following (slightly simplified) form (Figure 2).

I call this model the 'static' model of a tradition for reasons that will shortly become clear. It takes the form of a one-many chain of transmission: a generation of recipients acquires a tradition material and passes it on (even though not every member has to participate) to another generation of recipients. The tradition material in the chain of transmission is conceived in terms of causal (numerical) identity. Hence, while the recipients and tradents are many, the tradition material is one, and it is one and the same for each link of the chain of transmission. All faithful members of the tradition share the same set of beliefs, customs, teachings, practices, or procedures.

Besides Hobsbawm (1983: 2), who considers invariance the defining feature of traditions, ${ }^{8}$ Pieper (2010) advocates this model, at least with regard to religious traditions. Alluding to the once popular view that certain elements of the Christian doctrine are not included in the Bible but have been orally handed down from Jesus to his disciples (Kampling, 1991: 174-8), he likens the transmission of tradition materials to initiation rites: tradents are custodians of a tradition material; recipients submit to their authority. The point is not to discuss a topic but to inject (holy) knowledge: one person talks, the 
other listens. And the recipient does not even need to understand what he (or she) is being taught, but just to believe what the tradent himself (or herself) was told to believe. The recipient, Pieper says, is neither a conversation partner nor student of the earlier tradent or the originator of the tradition material, neither an equal nor contemporary, but a 'disciple ('Jünger') and heir to whom the tradition will be entrusted in the future. That is why Paul calls those who accept his message his 'sons' (Pieper, 2010: 11). In consequence, a tradition act according to the static conception is successful if the tradendum becomes a traditum: that is, what (from the perspective of the originator or earlier tradent) was supposed to be handed down must actually be handed down. Any mismatch between tradendum and traditum means that the 'disciples' have not listened carefully enough. The tradition act has failed (Pieper, 2010: 9-22).

I have presented this static model in the strictest possible form. A more moderate version could allow for some variation in the tradition material, and replace numerical identity with qualitative identity. Accordingly, adherents to the tradition would just share a common core of beliefs (or customs, etc.). The Traditionskern (i.e. kernel of the tradition material) would have to be one and the same for all recipients and tradents, but they could diverge from each other (intra- and inter-generationally) in regard to the margins of the tradition material. Still, there is no substantial difference between this more moderate and the strict version of the static model. In fact, Pieper could easily admit that only the Traditionskern of a tradition material constitutes the tradendum.

The static model certainly captures the self-understanding of many orthodox members of religious traditions. Moreover, as we saw in the previous section, Popper also seems to embrace it when associating traditions with uniformity and stasis in behavioural patterns. And given that uniformity and/or stasis is also presupposed by most socially valuable functions that are attributed to traditions in the literature, it is fair to say that the static model enjoys a certain popularity also outside of scholarship on religious traditions. However, while it is easy to understand why orthodox members of religious traditions will often consider the absence of alteration a constitutive feature of (their) tradition, it is not readily clear why a rational theory of tradition should rely on it. If a tradition material is presupposed to be of sacred origin, it ought not to be changed because of its origin, and perhaps it has a better chance of remaining unchanged if recipients do not even try to make sense of it. ${ }^{9}$ However, in the debate about the normativity of tradition, sets of secular beliefs (or customs, etc.) are also understood as tradition materials, no special authority is attributed to the originators of traditions materials (especially if, as Popper stresses, tradition materials usually emerge unintentionally), and deviation from a tradition is not considered a vice by definition. Why, then, should we believe that tradition materials (or Traditionskerne) ought - and could possibly - be the same for all adherents to a tradition and remain unchanged over time?

\section{The model of a living tradition}

An alternative to the static model provides that the tradition material (or Traditionskern) internalized by the various recipients may in some way differ among each other and change over time. By speaking of 'living tradition', I refer to such an understanding. ${ }^{10}$ Here, tradition takes the form of a many-many chain of transmission: there is more than 


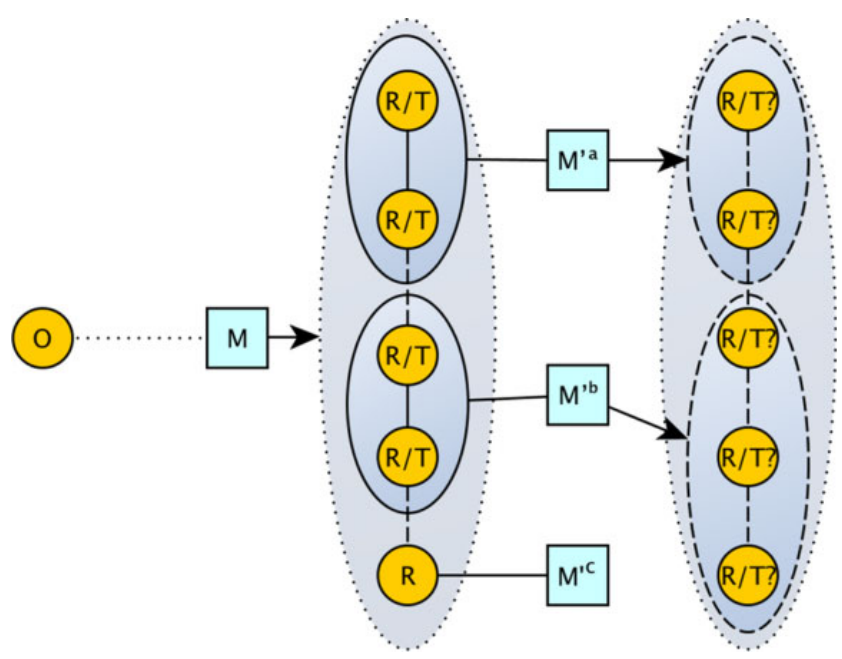

Figure 3. The model of a living tradition.

one co-existing recipient and tradent, and the sets of beliefs (or customs, etc.) that faithful members of the tradition hold may differ in certain regards. Preliminarily, we can adopt Payton's (2013) criterion for faithful membership in a tradition, which requires a very high degree of qualitative similarity. Accordingly, the tradition material of one generation of recipients needs to be (only) qualitatively similar, to a very high degree, to the preceding generation's tradition material. The tradition material received by simultaneously existing adherents may also merely display a high degree of qualitative similarity among one another. Figure 3 illustrates this model of a living tradition. Recalling the dress watch example, we might imagine that one group of recipients takes the original tradition material $(\mathrm{M})$ as prescribing that the dress watch be handed down to the first-born child $\left(\mathrm{M}^{\mathrm{a}}\right)$, a second group of recipients understands that a dress watch should be given to each child $\left(\mathrm{M}^{\mathrm{b}}\right)$, whereas a third recipient thinks that the dress watch must be transmitted only to the first-born son $\left(\mathrm{M}^{\mathrm{c}}\right)$. In Figure 3, the third recipient does not have any sons, and therefore cannot carry on the tradition. ${ }^{11}$

\section{Dynamic persistence}

The model of a living tradition might fit the purposes of a rational theory of tradition better than the static model. It is also tempting to reduce the latter's relevance to an 'internal' perspective on tradition that captures the self-understanding of members, and associate the former with an 'external' perspective on tradition that represents the standpoint of normative reason. ${ }^{12}$ Yet, Popper seems to express a widespread intuition when stating that we experience the creation of a new tradition rather than the continuation of an existing one, if a tradition material is modified (Popper, 1972: 125). Thus, we must assess whether the model of a living tradition that is based on the qualitative similarity criterion can be justified vis-à-vis the static model, and is, generally speaking, 
informative. Even if it were informative, we should still prefer, and therefore reflect upon, a conception of living tradition that stands a chance of conciliating internal and external perspectives (cf. Weber, 2015: 9). ${ }^{13}$ This section develops a theoretical justification for intra- and inter-generational alterations in tradition materials that do not affect the tradition's authentic persistence over time, and argues that we should replace qualitative similarity as criterion for the authentic continuation of a tradition by qualitative equivalence.

The model of a living tradition suggests that rivals in a dispute over authenticity (such as Shia and Sunni Muslims, Catholic and Protestant Christians, Stalinist and Trotskyist Communists, or Left and Right Hegelians) can be equally faithful adherents to one and the same tradition. Such rivals might share the beliefs $\alpha, \beta$, and $\gamma$, yet whereas one rival adds $\delta$, the other embraces $\epsilon$. According to the static model, only one of them can be right. After all, rivals in disputes over authenticity typically hold that their adversaries get the tradition material fundamentally wrong. (That is, the rivals disagree about whether $\delta$ or $\epsilon$ is a constitutive part of the tradendum, and if neither $\delta$ or $\epsilon$ is a constitutive part of the tradendum, then both rivals have thoroughly misunderstood the true meaning of the tradition material.) Reception theory offers a good reason to favour the model of a living tradition in this regard: tradition materials are polysemic, just like texts in the narrow sense of the word; they lack a discrete and objective structure of signification (Eco, 1979; Holub, 1984). Thus, the meaning of a tradition material (or text) is prestructured, but not entirely pre-determined, by its originator (or author). Recipients necessarily play a co-constitutive role in the creation of meaning by resolving ambiguities and specifying vagueness in some form or another. The process of internalization of a tradition material, therefore, is one of making sense rather than one of listening. Recipients are active interpreters, not passive 'Jünger' - regardless of whether they are consciously aware of their active role in receiving tradition materials. ${ }^{14}$ In consequence, there is always more than one conceivable way of carrying on a tradition. Two or more persons can be equally faithful adherents of one and the same tradition despite having diverging understandings of the tradition material.

However, the criterion of qualitative similarity allows for greater modifications in the tradition material than can be justified by recourse to reception theory. Instead of merely resolving ambiguities and specifying vagueness, a recipient could say that she passes on Hegelianism except for one central line of thought. Qualitative similarity would still apply. Moreover, the recipient could decide to single out one line of thought by lottery. The deliberate arbitrariness by which an element of the original tradition material would then be abandoned apparently violates the value of authenticity. In addition to that, the qualitative similarity criterion turns out to be over-inclusive once a long-term perspective is taken in. Qualitative similarity, on Payton's (2013: 43) account, is required only between consecutive but not distant links in the chain of transmission. ${ }^{15}$ In consequence, a late recipient might not share a single aspect of the original tradition material. Figure 4 illustrates this possible long-term consequence.

Doubts arise as to whether the concept of tradition, thus understood, could still be useful. ${ }^{16}$ Arguably, we would just formalize the fate that the transmission of beliefs (or customs, etc.) typically suffers in situations where recipients either lack efficient means (as e.g. in pre-literate societies) or the intent (as e.g. in a 'whisper down the line') to pass 


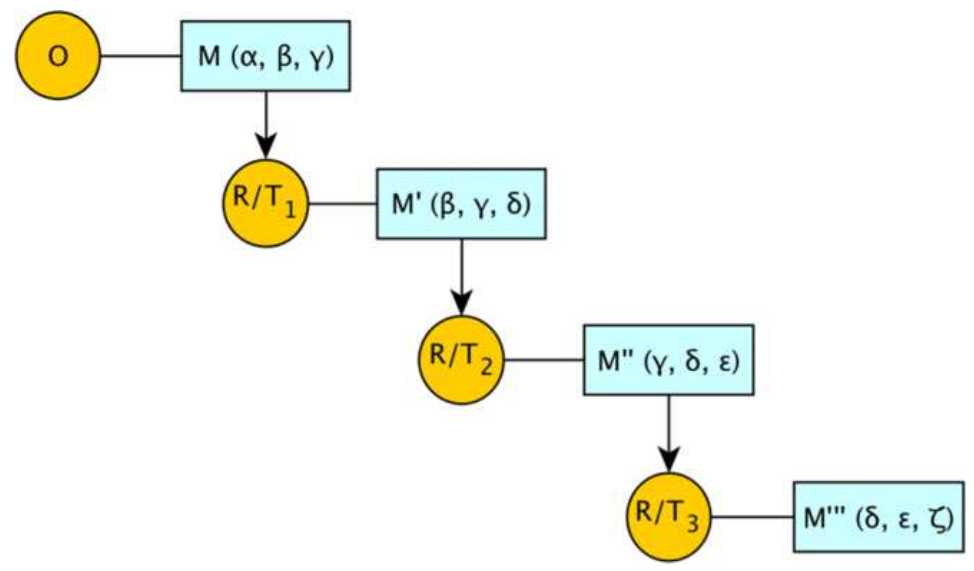

Figure 4. Long-term consequences of the qualitative-similarity criterion.

on the original message. For situations of the first kind we should be able to say that a tradition was lost, and for situations of the second kind, that the tradition was deliberately abandoned. The question of efficient means needs no further discussion for the present purposes. But the presence of some conservative intent appears to be important for a meaningful conception of tradition. Otherwise we would have to conclude that two diverging doctrines are the material of one and the same tradition whenever they are qualitatively similar to a very high degree and stand in a causal relationship to each other. Perhaps it is true that atheism developed out of Christianity and that their morality differs only slightly when compared with other creeds (Bloch, 2009). To claim that atheism and Christianity are therefore one and the same tradition, as does Žižek (2012: 115), appears excessive. ${ }^{17}$

To build the conservative intent that appears to be important for a meaningful conception of tradition into the model, I propose to replace qualitative similarity with equivalence. ${ }^{18}$ That is, a tradition act is successful if the set of beliefs, (or customs, etc.) held by recipients/tradents has the same overall point or prima facie purpose in the recipients'/tradents' respective contexts of living. This allows us to explain why a recipient's tradition material (M') may, under certain conditions, differ from the tradent's version (M) but nevertheless be true to it and in some sense even be the same, as well as how and how much M' may legitimately differ from M. The guiding idea is that a later generation must express its continuing fidelity to an earlier tradition material by the identical tradition material $\left(\mathrm{M}=\mathrm{M}^{\prime}\right)$ if the context of living has not changed significantly, whereas it has to express its continuing fidelity to this earlier tradition material by a distinct tradition material $\left(M \neq M^{\prime}\right)$ if the context of living has actually changed in relevant aspects. Whereas in the former case, any modification (that goes beyond the resolution of vagueness and specification of ambiguities) of the tradition material would mean betraying the tradition, in the latter case, substantial modifications (apart from resolving vagueness and specifying ambiguities) must be made to counterbalance the changes in the respective contexts of living. The point of reference for such necessary 
substantial modifications by the recipient, to repeat, is the overall point or prima facie purpose of the original tradition material, not - what Hobsbawm (1983: 6) observed is typical of invented traditions - some extrinsic ideological objective.

To see why the authentic continuation of a tradition requires a context-sensitive reception of its tradition material, another analogy with the interpretation of texts is helpful. A reader of an Italian Renaissance text who conducts a text-immanent analysis of its propositional content is vulnerable to anachronisms. He or she must take language change into account and interpret the text in the light of the vernacular and intellectual conventions in use back then (Skinner, 2002: Chapters 1,2). Just as a historical text requires re-contextualization to grasp its meaning, so a predecessor's tradition material needs be updated to have the same prima facie purpose under a changed context of living. Technological, economic, social, cultural, environmental, and arguably all kinds of external developments may after all affect the role that a tradition material plays in one's life. The right to keep and bear arms, as stated in the Second Amendment to the US Constitution, is likely to have had a different prima facie purpose before a regular army and police force was established. The legal duty to carry arms outside settlements, as required in Svalbard, would mean something completely different if climate change exacerbated and destroyed the natural habitat of polar bears.

In sum, a faithful member of a tradition must re-create the tradition material in such a way that it (in)forms the ways of thinking and acting of the present generation of recipients in the face of their current context of living, just as the tradition material (in)formed the preceding generation's ways of thinking and acting in their historical circumstances. Formally expressed, we can say that the model of tradition that builds upon the qualitative equivalence criterion holds that a recipient authentically continues a tradition iff (1) there is some tradition founder who originates $M$; (2) the recipient receives $M$ directly or indirectly from the tradition founder; (3) the recipient develops $\mathrm{M}^{\prime}$ because (in a causal sense) of $\mathrm{M}$; and (4) $\mathrm{M}^{\prime}$ is qualitatively equivalent to $\mathrm{M}$, in the sense that the recipient's modifications of $\mathrm{M}$ are limited to resolved ambiguities and specified vagueness, as well as actualizations designed to counterbalance the relevant changes in conditions of living that occurred in the meantime.

This model of tradition avoids the problem of under-inclusiveness from which the static model with its identity criterion suffers: it allows for significant intra- and intergenerational heterogeneity of tradition materials, and shows in what sense it is not meaningless to say that a tradition material can persist as one and the same (namely, context-sensitively viewed), even though it varies (namely, context-independently viewed) among simultaneously existing members of a tradition as well as across generations. On the other hand, the proposed model avoids the aforementioned problems that are associated with models relying on the qualitative similarity criterion: it avoids over-inclusiveness by ruling out deliberate arbitrariness and by integrating conservative intent. Two doctrines can be the subject of two rather than one tradition even though they are qualitatively similar to a very high degree and one of them was developed because (in a causal sense) of the other. Moreover, it allows for the possibility that some set of beliefs (or customs, etc.) authentically carries on a tradition even though it is dissimilar to earlier versions. After all, recipients are supposed to counterbalance relevant circumstantial change, and if the circumstances since the originator's (or even the preceding recipient's) 
times have changed dramatically, the modifications of the tradition material will have to be dramatic, too.

To illustrate the peculiarity of the proposed model of tradition, consider a variant of the aforementioned case of atheism. Is an atheist, who developed his or her 'humanism' out of Christian caritas, an authentic adherent to the Christian tradition? ${ }^{19}$ The qualitative similarity model suggests that the atheist is a faithful member of the Christian tradition, provided that his or her humanism displays a very high degree of similarity to caritas. The static model suggests that the correct answer depends on whether the acknowledgment of God's existence is essential for the understanding of the original version of caritas. If it is, the atheist is no authentic adherent because he or she denies God's existence. If it is not, the atheist's humanism might well preserve the tradendum of caritas (and Christian believers misunderstand the real meaning of caritas if they took the acknowledgment of God's existence to be essential). Now, the proposed model with the qualitative equivalence criterion understands that the correct answer may well depend on the importance of the acknowledgment of God's existence for the true meaning of caritas, but allows for a third possibility: an atheist can authentically continue the tradition of caritas just as many Christian believers, provided that relevant circumstances have changed significantly enough to justify his or her humanist reinterpretation. Suppose, for instance, that for a long time caritas could only be justified by reference to an extra-human entity. Due to philosophical innovation, however, it has meanwhile become possible to justify caritas alternatively in a secular way. Under contemporary philosophical circumstances, caritas could therefore legitimately and authentically be rearticulated in terms of an atheist humanism (without ruling out Christian varieties). In other words, philosophical innovation might have made the once presumably essential acknowledgment of God's existence irrelevant for grasping the true meaning of caritas.

Hence, the proposed model of tradition provides a sufficiently clear understanding of why, how, and how much tradition materials may change; it succumbs to neither over- nor under-inclusiveness; and it promises to be informative when applied to concrete cases. What difference does the proposed model make to our understanding of the socially valuable functions that traditions are supposed to serve? The following section addresses this question by focusing in particular on the relationship of traditions and institutions.

\section{Tradition and institutional modernization}

The concept of a living tradition has several implications for a re-adjustment of Popper's sketch of a rational theory of tradition. The claim that traditions attune people's behaviour, order and co-ordinate the social word, bring predictability, and thus facilitate individual and collective rational action, must be relativized. Traditions certainly allow recipients to gain deliberative efficiency, as they need not develop beliefs (or customs, etc.) for every aspect of social life all by themselves. Furthermore, traditions foster contiguity in ways of thinking and acting, as well as feelings of identification and historical embeddedness among recipients and their respective tradents. Yet among the members of one generation and across generations of recipients, traditions are as likely 
to create a shared horizon of understanding and similarity in behaviour as they are prone to provoke alterity, schisms, and alienation.

The absence of uniformity in ways of thinking and acting among the members of a tradition also gives rise to doubts that traditions serve as unproblematic stabilizers for institutions through animating individuals to run them in accordance with their prima facie social purposes. At least in addition to the stabilization function, the concept of a living tradition underpins the idea that also the heterogeneity of tradition materials among the members of one generation of recipients, and endogenous change of tradition materials over time, serve a valuable function for the maintenance of a society's institutional order.

To see why this might be so, recall that institutions share many similarities with tradition materials: they also present or imply patterns or images of actions and the beliefs requiring, recommending, regulating, permitting, or prohibiting the reenactment of those patterns (cf. Popper, 1972: 133; Shils, 1981: 20). But two important differences can be discerned. First, it is not constitutive of institutions that they are the subjects of transmission processes. And, second, the patterns of actions presented by institutions take a solidified and centrally organized form. Institutions embody juridified patterns of action, and manage and organize compliance. For reasons of clarity, one may thus speak of social traditions and legal institutions. Institutionalized patterns of action can be inventions or the material of a tradition. The Catholic Church, for instance, can be regarded as an attempt to institutionalize the Christian teaching. In such cases of institutionalized traditions, the ways of thinking and acting called for by a tradition material are centrally interpreted and legally fixed, yet - and this is the decisive point - the tradition does not cease to persist, flourish, and reproduce its material in a heterogeneous manner throughout the transmission process. The tradition lives on, whereas institutions are born dead. By way of having its material handed down, received, and adapted to changing circumstances, the tradition permanently presses for re-institutionalization; it counteracts the finality proclaimed by legal fixation and thus counteracts political closure. As the tradition does not speak with one voice, it is not itself a decision-making procedure. Rather, it serves as a decentralized data-gathering system that informs policy-making about perceived needs and available options for the modernization of established institutions.

Consider, for example, the interplay of the tradition and institution of marriage in the Federal Republic of Germany. The pattern of engaging in a marital relationship was the material of a tradition in Germany long before its first fixation and legal explication in 1949. The law, then, defined marriage as a life-long monogamous relationship among adults of different sex. It thus made room for some social practices of marriage prescribed by certain branches of the tradition, but obviously not all of them, such as lifelong monogamous relationships among persons of the same sex. In the last two decades, the proposal to open the legal institution of marriage to persons of the same sex has gained momentum. In public discourse, this proposal is commonly understood as emancipatory and 'anti-traditional', and, in the eyes of its advocates, justified by the principle of non-discrimination. However, same-sex inclusive marriage can be perfectly grasped in terms of the authentic continuation of the tradition of marriage, despite its previous heterosexual requirement, and even among those tradition branches that consider mutual care, romance, and economic risk-sharing to be of secondary relevance to producing and 
raising descendants. In other words, changing external circumstances such as biomedical innovations increasingly suggest that same-sex inclusive marriage is an adequate 'timely update' (cf. Beckstein 2014, 32) of the original tradition material. After all, heterosexual intercourse is no longer a necessary condition for fertilization, and the nutritional quality of infant formulas has immensely improved, such that breast-feeding is no longer strictly necessary. The sex of spouses is largely irrelevant to the success or failure of marriages that are justified in relation to the function of reproduction.

Of course, opponents of same-sex inclusive marriage are likely to object to this argument by making one of the following two claims. They might argue that circumstances have not yet changed sufficiently enough to marginalize the biological differences between man and woman. However, they would thus accept the provided account of a living tradition along with its modernization function and implicitly admit that times will at some point be ripe for same-sex inclusive marriage. Sooner or later, according to this objection, authentic adherents of the tradition of marriage will have to consider the sex of spouses an anachronistic criterion, and when the time has come will have to be determined by the medical sciences, not philosophers, the citizenry, or politicians. Alternatively, they might go further and assert that circumstances cannot possibly change sufficiently to legitimize the extension of marriage to same-sex couples because marriage is essentially a union between one man and one woman. In this case, however, it would be insufficient to invoke empirically observable biological (and social) difference between the sexes and the risk of leaving the argumentative terrain that can be covered by public reason would be high. ${ }^{20}$

\section{Conclusion}

The present article started out from the observation that scholarship on the functions and normativity of traditions often stays on shaky conceptual grounds. Considering different models of tradition, I have suggested that a model of living tradition, which allows tradition materials to diverge intra- and inter-generationally, sits more easily within a rational theory of tradition than a static model that requires homogeneity. Contrary to what Hobsbawm (1983: 1) suggested at the very beginning of his famous article, a tradition's continuity with the past need not be broken or be factitious if recipients give the tradition material a novel form. To specify and justify a model of living tradition, I have argued that causal equivalence is a more convincing criterion for the authentic continuation of a tradition than causal similarity.

This conception of tradition, I believe, provides a more solid basis for future inquiries into the functions and normativity of traditions than the accounts that have, sometimes in sketchy shape, informed earlier analyses. Adopting it suggests that we must relativize the function, frequently attributed to traditions, of attuning people's ways of thinking and acting. Moreover, working in the opposite direction of Popper's argument that traditions motivate individuals to run institutions in accordance with their prima facie purposes, we have seen that disagreement among adherents nurtures deliberative processes of policymaking and expedites institutional reform. Living traditions thus serve as catalysts, even though not quite as drivers (as Hayek's and MacIntyre's respective theories of cultural evolution suggest ${ }^{21}$ ), for processes of re-institutionalization. 
When illustrating this modernization function and equivalence criterion with the examples of marriage and caritas, we touched upon the difficulties associated with the assessment of social disputes over the authentic continuation of a tradition. The proposed account does of course not, by itself, resolve these disputes. It cannot tell us whether this or that tradition managed to persist as one tradition despite (synchronically or diachronically) heterogeneous tradition materials, or whether it has effectively split into one faithful tradition and heretical sects, or whether it was completely abandoned. Empirical assessment of the specific traditions and changed circumstances is needed. Yet, the conception of a living tradition can guide this empirical assessment in at least three relevant ways. First, it helps to reject claims as to the exclusive true inheritance of a tradition; principles such as the 'Extra ecclesiam nulla salus' are ruled out. Because of the polysemic nature of tradition materials it is always possible that two or more receptions are equally faithful to the original.

Second, it casts doubts on verbatim reproductions of an earlier generation's interpretation of a tradition material. A tradition is authentically continued only if the causal equivalence criterion is met. A disputant's proposal must be a timely update of the original version. His or her version of the tradition material must counterbalance circumstantial changes and thus have the same prima facie purpose in his or her world, what the original version had in the respective contexts of living of earlier faithful members and the founder of the tradition. The conservative imperative inherent in traditions calls for keeping the transmitted set of beliefs (or customs, etc.) in step with changing external conditions. Since our world is characterized by an abundance of complexity, there will of course be uncertainty about which relevant circumstances have changed, and how substantial these changes are. Yet, adopting the conception of living tradition reminds us that verbatim reproductions of a tradition material imply the claim that relevant circumstances have not changed at all, which, in many situations, will not be particularly convincing.

Finally, the conception of a living tradition suggests that counterfactual approval is not a particularly relevant strategy for determining the genuine prima facie purpose of a tradition material. Not infrequently, rivals in disputes over authenticity suggest that the best way to find out whether $\mathrm{X}$ or $\mathrm{Y}$ is a true inheritor of, say, the Christian, Communist, or Hegelian tradition is to consider what Jesus, Marx, or Hegel would say upon coming back to life (Lebens, 2013a, 2013b). The proposed conception of living tradition suggests that we should not care too much about counterfactual approval. For one, these tradition founders might know better than anybody else what their teachings originally meant, but have not experienced how the world has changed since. Resurrecting them from the dead does not accomplish the task of counterbalancing developments that have occurred in the meantime. On the other hand, tradition founders, even though they are the authors of the tradition material, are not interpretive sovereigns. Recipients necessarily play a co-constitutive role in the determination of meaning. The founder of a tradition, even if resurrected from the dead, could not do the thinking for us. Perhaps, therefore, it is a good way to say that starting a tradition, tradition founders bestow a path-dependent mandate upon recipients to re-interpret and update their original set of beliefs (or customs, etc.), and in this sense pass the baton for the tradition material along with the tradition material itself. 


\section{Acknowledgments}

I am grateful to Kristóf Nyíri, Nomi Claire Lazar, Jack Williams, Vanessa Rampton, two anonymous reviewers and Gerard Delanty from EJST for comments on previous drafts of this paper.

\section{Declaration of Conflicting Interests}

The author declared no potential conflicts of interest with respect to the research, authorship, and/ or publication of this article.

\section{Funding}

The author disclosed receipt of the following financial support for the research, authorship, and/or publication of this article: This work was supported by the Swiss National Science Foundation under Grant P300P1_161046.

\section{Notes}

1. For the second and third aspect, see especially Scheffler (2010: 291). For the last two aspects, see especially Marsh (2012) and Nyíri (1995).

2. By authenticity, I understand 'the quality or fact of accurately reflecting a model or exemplar', for instance, the condition of an idea or practice of being true to some earlier belief, custom, or teaching. My understanding follows the Oxford English Dictionary online edition's entry on 'authenticity' (3d), available at: http://www.oed.com/ (accessed November 17, 2015).

3. See, in particular, the recent debate over traditions and true successors in the Social Epistemology Review and Reply Collective: available at: http://social-epistemology.com/2014/08/ 09/true-succession-and-inheritance-of-traditions-looking-back-on-the-debate-john-williams/ (accessed January 26, 2016). See also Freeden (1998: 324) and Tännsjö (1990: 47).

4. For Popper's conversation with Hayek and Oakeshott on traditions, see Birner (2014) and Jacobs and Tregenza (2013).

5. Popper appears to approve of the 'traditionality hypothesis', according to which human cognition cannot step outside of formed ways of thinking. For an exposition and a discussion of this hypothesis, see Annas (1989) and Dittmann (2004: 38, 140-1).

6. Shil's insight reveals a shortcoming in Hobsbawm's (1983: 2-3) understanding of tradition that equates symbolizations of tradition materials (e.g. a watch, a judge's robe and wig) with the tradition material itself.

7. This conclusion conforms to Hobsbawm's understanding of invented traditions. According to Hobsbawm (1983: 2), the peculiarity of invented traditions is that their inauguration comes along with a (factitious) reference to a historic past.

8. However, what Hobsbawm (1983: 2) terms 'custom' comes close to the second model of tradition ('living tradition').

9. Early traditionalist critics of Enlightenment rationalism defended the consecration of the status quo by making an explicit analogy to the Christian tradition. Doubting the truth of the Christian tradition is a manifestation of apostasy, Bonald argued. Questioning 'natural' traditions that maintain the estate-based society, he continued, amounts to political atheism. Cf. Spaemann (1998: 151).

10. The term 'living tradition' is also common in Christian theology. In Catholic thought, however, the 'living' nature of (the Christian) tradition is typically associated with the on-going revelation of the Word of God through the Holy Spirit. See e.g. Casarella (2015: 221-2). 
Ottati's (1984) Calvinist-inspired account of Christianity as living tradition comes closer to the model presented in Figure 3.

11. Among the more important aspects not reflected in Figure 3 is the possibility that a recipient receives the tradition material (e.g. Hegelianism) from more than one source.

12. For the distinction of internal and external perspectives on traditions, see Ruben (2014). Dworkin (1986: 13) elaborated on this distinction in the context of legal questions.

13. Weber warns against 'purely transcendental examinations' that 'operat[e] aloof from the world they seek to address', and argues that the composition and expectations of relevant audiences must not be left out of consideration. I will return to the empirical assessment of claims made in disputes over authenticity in the Conclusion. Suffice it to say that my aim in this respect is primarily to develop a formal conception of (the authentic continuation of a) tradition that is acceptable both from an 'external' as well as an 'internal' perspective, i.e. observers and adherents of particular traditions.

14. Note that this reception theoretical view of the pre-structured nature of tradition materials does not coincide with the Traditionskern of moderate versions of the static model of a tradition. Ambiguities and vagueness affect all aspects (i.e. $\alpha-\epsilon$ in the aforementioned example) of a tradition material, even though perhaps not in equal measure.

15. In full, the definition of true inheritance of a tradition I refer to reads:

$\mathrm{Y}$ is a true inheritor of a tradition $\mathrm{T}$ iff (i) there is some $\mathrm{X}$ that originates $\mathrm{T}$; (ii) $\mathrm{S}_{\mathrm{X}}$ and $\mathrm{S}_{\mathrm{Y}}$ stand on opposite ends of a chain of $S_{S}$ (which may include only $S_{X}$ and $S_{Y}$ ); (iii) each link $S_{n}$ is developed after $S_{n-1}$; (iv) each link $S_{n}$ is qualitatively similar, to a very high degree, to $S_{n-1}$; and (v) the holder of $S_{n}$ develops $S_{n}$ because the holder of $S_{n-1}$ develops $S_{n-1}$.

16. I refrain from recounting the ship-of-Theseus problems that loom ahead at this point.

17. Tännsjö (1990) also embraces the qualitative similarity criterion in his discussion of traditionalism, admits its over-inclusiveness and suggests a democratic vote by the people concerned to decide disputes. I doubt that this leads very far. Disputants who are allowed to be judges in their own case must be expected to opt for their own respective version of the tradition material. The decisive criterion for authentic continutation of a tradition would be the quantity of adherents:

The upshot of this is that no precise, abstract characterization of traditionalism can be made. The concept has deliberately been cast in vague terms. But how are we, in a particular political context, to resolve the vagueness? The standard solution is as follows. When assessing a suggested political reform we have to decide whether it is faithful to a well-established existing idiom of conduct or not. This is a matter of identity. Would the suggested reform exchange one idiom for another, or would it preserve an existing idiom, possibly enhancing it? Well, who is to tell? The people concerned; I think the conservative ought to answer. To be sure, any suggested reform would preserve some traits of some existing idiom while changing others. Identity is never a matter of exact similarity. Whether two different states of some institution, say, are states of the same institution or not, depends on whether certain relevant similarities and other relations (where certain causal ones are especially important) hold between the two states. What similarities and what other relations, then, are relevant? This is what has to be decided by the people concerned by a suggested reform. (Tännsjö, 1990: 47)

18. Rudimentary articulations of this criterion can arguably be found in MacIntyre (1998: 350-5) and Ottati (1984: 82, 86).

19. I am grateful to [Robert E. Goodin] for drawing my attention to the test US courts applied to determine whether atheists could qualify as conscientious objectors to war and be excused from conscription. 
20. For a sophisticated argument along these lines, see Girgis, Anderson and George (2012), who argue that same-sex couples are ineligible for marriage because their sexual intercourse lacks a dynamism toward procreation. For a critique, see Macedo (2015: 41-3).

21. For Hayek, see Voigt (1991). For MacIntyre, see Milibank (2015) and Porter (2003: 52).

\section{References}

Annas J (1989) MacIntyre on traditions. Philosophy and Public Affairs 18(4): 388-404.

Beckstein M (2014) Traditions and true successors: a few pragmatic considerations. Social Epistemology Review and Reply Collective 3(3): 30-36.

Birner J (2014) Popper and Hayek on reason and tradition. Philosophy of the Social Sciences 44(3): 263-81.

Bloch E (2009) Atheism in Christianity: The Religion of the Exodus and the Kingdom. New York: Herder and Herder.

Casarella P (2015) 'A healthy shock': tradition and the epiphany of beauty. In: Grimi E (ed.) Tradition and Innovation. Newcastle Upon Tyne: Cambridge Scholar Publishing, pp. 220-41.

Dittmann K (2004) Tradition und Verfahren. Norderstedt: BoD.

Dworkin R (1986) Law's Empire. Cambridge, MA: Belknap Press.

Eco U (1979) A Theory of Semiotics. Bloomington: Indiana University Press.

Freeden M (1998) Ideologies and Political Theory. A Conceptual Approach. Oxford: Oxford University Press.

Girgis S, Anderson R and George R P (2012) What Is Marriage? Man and Woman: A Defense. New York: Encounter Books.

Hobsbawm E (1983) Inventing traditions. In: Hobsbawm E and Ranger T (eds) The Invention of Tradition. Cambridge: Cambridge University Press, pp. 1-14.

Holub R C (1984) Reception Theory. London: Methuen.

Jacobs S and Tregenza I (2013) Rationalism and tradition: the Popper-Oakeshott conversation. European Journal of Political Theory 13(1): 3-24.

Kampling R (1991) Tradition. In: Eicher P (ed.) Neues Handbuch theologischer Grundbegriffe, vol. 4. Munich: Kösel, pp. 169-82.

Lebens S (2013a) True successors and counterfactual approval. Social Epistemology Review and Reply Collective 2(10): 26-31.

Lebens S (2013b) Counterfactual approval and idiosyncratic counterfactual approval. Social Epistemology Review and Reply Collective 2(11): 65-9.

Macedo S (2015) Just Married: Same-Sex Couples, Monogamy, and the Future of Marriage. Princeton, NJ: Princeton University Press.

MacIntyre A (1992) Three Rival Versions of Moral Enquiry: Encyclopedia, Genealogy and Tradition. Notre Dame, IN: University of Notre Dame Press.

MacIntyre A (1997) After Virtue: A Study in Moral Theory. Notre Dame, IN: University of Notre Dame Press.

MacIntyre A (1998) Whose Justice? Which Rationality? Notre Dame, IN: University of Notre Dame Press.

Marsh L (2012) Oakeshott and Hayek: situating the mind. In: Franco P and Marsh L (eds) $A$ Companion to Michael Oakeshott. University Park, PA: Penn State Press, pp. 248-67.

Milibank J (2015) Tradition: after and beyond MacIntyre. In: Grimi E (ed.) Tradition and Innovation. Newcastle Upon Tyne: Cambridge Scholar Publishing, pp. 242-54. 
Nyíri C (1995) Introduction: notes towards a theory of tradition. In: Nyíri C (ed.) Tradition. Vienna: IFK, pp. 7-32.

Oakeshott M (1965) Rationalism in politics: a reply to Professor Raphael. Political Studies 13: 89-92.

Oakeshott M (1991) Rationalism in politics. In: Rationalism in Politics and Other Essays. Indianapolis: Liberty Fund, pp. 5-42.

Ottati D F (1984) What it means to stand in a living tradition. In: Boulton W, Kennedy T and Verhey A (eds) From Christ to the World: Introductory Readings in Christian Ethics. Grand Rapids, MI: Eerdmans, pp. 79-87.

Payton J (2013) Ruben's account of traditions and true successors: two modifications and an extension. Social Epistemology Review and Reply Collective 2(11): 40-6.

Pieper J (2010) Tradition: Concept and Claim. South Bend, IN: St. Augustine's Press.

Popper K R (1972) Towards a rational theory of tradition. In: Popper K R Conjectures and Refutations. The Growth of Scientific Knowledge, 4th edn. London: Routledge and Kegan Paul, pp. 120-35.

Porter J (2003) Tradition in the recent work of Alasdair MacIntyre. In: Murphy M C (ed.) Alasdair MacIntyre: Contemporary Philosophy in Focus. New York: Cambridge University Press, pp. 38-69.

Ruben D-H (2014) Internal and external perspectives: reply to Beckstein. Social Epistemology Review and Reply Collective 3(3): 55-6.

Scheffler S (2010) The normativity of tradition. In: Scheffler S Equality and Tradition: Questions of Value in Moral and Political Theory. New York: Oxford University Press, pp. 286-311.

Shils E (1981) Tradition. Chicago: The University of Chicago Press.

Skinner Q (2002) Visions of Politics. Vol. 1: Regarding Method. Cambridge: Cambridge University Press.

Spaemann R (1998) Der Ursprung der Soziologie aus dem Geist der Restauration. Studien über L. G.A. de Bonald. Stuttgart: Klett-Cotta.

Tännsjö T (1990) Conservatism for Our Time. London: Routledge.

Voigt S (1991) Die evolutionsorientierte Theorie der Verfassung. Zeitschrift für Wirtschaftspolitik 40(2): 96-108.

Wall S (2015) Political morality and the authority of tradition. Journal of Political Philosophy. Epub ahead of print 22 May 2015. DOI: 10.1111/jopp.12058.

Weber R (2015) Representing tradition: an analysis of Tu Weiming's Confucianism. International Communication of Chinese Culture. Epub ahead of print November 2015. DOI: 10.1007/ s40636-015-0041-y.

Žižek S (2012) Less Than Nothing: Hegel and the Shadow of Dialectical Materialism. London: Verso.

\section{Author biography}

Martin Beckstein is a Swiss National Science Foundation Fellow at the University Center for Human Values, Princeton University. He has published, among other things, The Politics of Economic Life (Routledge, 2015) and co-authored Politische Ideengeschichte: Interpretationsansätze in der Praxis (Vandenhoeck \& Ruprecht, 2014). Recently, he has also served as a guest editor for The Monist's special issue on conservatism (2016, 99/4). 